Article

\title{
Pore Structure Degradation of Different Cement Mortars Exposed to Sulphuric Acid
}

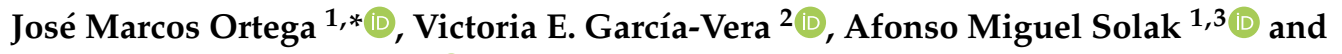 \\ Antonio José Tenza-Abril ${ }^{1}$ (D) \\ 1 Department of Civil Engineering, University of Alicante, 03080 Alicante, Spain; \\ afonsosolak@gmail.com (A.M.S.); ajt.abril@ua.es (A.J.T.-A.) \\ 2 Departamento de Arquitectura y Tecnología de la Edificación, Universidad Politécnica de Cartagena, \\ 30203 Murcia, Spain; victoria.eugenia@upct.es \\ 3 CYPEIngenieros S.A., 03003 Alicante, Spain \\ * Correspondence: jm.ortega@ua.es; Tel.: +34-96-5903-400 (ext. 2470)
}

Received: 12 November 2019; Accepted: 29 November 2019; Published: 5 December 2019 check for
updates

\begin{abstract}
Acid attack causes the deterioration of construction material surfaces. The objective of this study was to investigate the degradation of different types of cement mortar in terms of variations in pore size distribution obtained by mercury intrusion porosimetry (MIP), mass loss, and compressive strength. The mortars were manufactured with nanosilica, zinc stearate, and an ethyl silicate coating. After curing (28 days), the samples were subjected to acid exposure for 90 days, immersed ina solution $(3 \% \mathrm{w} / \mathrm{w})$ of sulphuric acid $\left(\mathrm{H}_{2} \mathrm{SO}_{4}\right)$. The results indicate that the mortars showed a more refined microstructure, with a higher proportion of smaller pores $(<100 \mathrm{~nm})$ compared to the control mortar. The 28-day and 90-day compressive strength variations of mortars were also determined by observing pronounced reduction due to the appearance of expansive compounds responsible for microcracking.
\end{abstract}

Keywords: microstructure; durability; acid rain; zinc stearate; ethyl silicate; nanosilica

\section{Introduction}

Acid rain can be produced by natural effects (e.g., volcanic eruptions), but it is human action that causes the most emissions of sulphur and nitrogen oxides (e.g., metallurgical industry, energy production processes, and heating system). These constituents dissolve in contact with atmospheric water and generate sulphuric and nitric acid, which subsequently fall to the earth's surface; this is known as acid rain. Moreover, the chemical substances that generate acid rain, before precipitation and due to the wind, can travel long distances from the actual polluting region [1]. Acid rain $(\mathrm{pH}<5)$ causes the deterioration of construction material surfaces on which the pollutants are deposited. In addition, several studies show that acid rain generates a layer of gypsum on the substrate [2,3] due to a chemical reaction of sulphuric acid with products of cement hydration (such as calcium silicate hydrate and calcium hydroxide) [4,5], and with calcium carbonate [6] that usually comes from aggregates utilised in the manufacturing of cementitious materials.

Since cementitious materials are very likely to be in contact with acidic environments (such as acid rain, infrastructures in contact with groundwater and sanitation networks) it is necessary to study admixtures that can improve the resistance of cementitious materials to aggressive environments and the effects of these admixtures. This study compares three admixtures that have already been used with good results in acid attacks, but have not been tested to identify which ones have better performance. The tested materials are nanosilica, zinc stearate, and ethyl silicate; these admixtures are utilised to increase the durability of cementitious materials, as explained below. 
Nanosilica has been employed as an alternative to silica fume in the manufacturing of cement-based materials [7]. Norhasri et al. state that the reactions of nanosilica in concrete are similar to that of silica fume or micro silica as regards strength and durability improvements [8]. However, Qing et al. [9] indicate that on using nanosilica as admixture instead of silica fume, a higher compressive strength is obtained, especially in the early stages. Nanosilica is currently being used in cementitious materials to increase: (i) resistance, due to its pozzolanic effect [10,11]; and (ii) durability, due to the reduction of porosity and improvement of the microstructure of cement-basedmaterials [12]. A recent study analysed the effect of nanosilica on concretes exposed to sulphuric acid; the results indicated a better performance of nanosilica concretes, since their compressive strength was greater and mass loss was lower [10].

Water-repellent materials have been used extensively in the manufacturing of cementitious materials to prevent the absorption of water. Its use is normal when mortars must be preserved from water or rain. Lanzón et al. [13] studied several metallic soaps (zinc stearate, calcium stearate, and sodium oleate) and powdered silicone on mortars; their work showed that when mortars are exposed to sulphuric acid, a layer of gypsum is formed and some disintegration takes place. Despite the previous effects, the water-repellent admixtures improved the mortars' durability in terms of acid attack resistance. Zinc stearate was also used as an admixture in adobes, achieving good results as regards acid attack resistance [14]. Calcium stearate was studied in cement pastes under sulphate attack, and an increase in resistance to sulphate attack was found [15].

Ethyl silicate (also called TEOS-tetraethyl orthosilicate) is a versatile product that has been used since the early 20th century for various applications (e.g., stone consolidant, ceramic binder, adhesive, source of amorphous silica) [16]. Currently, it is one of the most used products in the consolidation of architectural heritage materials, such as bricks, stone, and lime mortars. Also, it can be used as surface treatment on cement-based materials for its pozzolanic effect [17-19]. Ethyl silicate reacts with environmental humidity and the free water in the material transforms into silica gel, releasing ethyl alcohol (which evaporates and does not produce any damaging residue on the material surface). Silica gel gives the treated surface new mechanical properties, due to the strong chemical bond that is established with the substrate. In addition, ethyl silicate reduces the water absorption of cementitious materials, carbonation depth, and chloride diffusion coefficient [18]. A recent study [20] showed that ethyl silicate improves the resistance of earthen materials to acid rain. However, this material is little studied in cementitious materials exposed to acidic environments.

This study evaluates the effects of acid rain, simulated with a solution of sulphuric acid, on mortars made with three types of admixtures (zinc stearate, nanosilica, and an ethyl silicate coating). The effects of the acid attack were analysed in terms of microstructure, compressive strength, and mass loss.

\section{Materials}

Limestone sand and Portland cement were utilised for the mortars used in this study. The designation of the cement, according to the UNE-EN 197-1 standard [21], corresponds to a CEM I 52.5 (CEMEX, Madrid, Spain). The particle size distribution of the sand was analysed according to the UNE-EN 933-1 standard [22], obtaining a maximum size of $4 \mathrm{~mm}$. The dosage employed consisted of a water-to-cement ratio of 0.45 and an aggregate-to-cement ratio of 3 . Moreover, a superplasticiser (Sika Viscocrete-5980) was used to achieve adequate workability (1.5\% of the cement weight). Mortar of zinc stearate (ZS) was obtained by adding $2 \%$ weight-by-weight (w/w) of ZS (Alfa Aesar, Ward Hill, MA, USA) to the cement weight. The mortar of nanosilica (NS) was obtained by adding $2 \% \mathrm{w} / \mathrm{w}$ of a suspension of amorphous nanosilica (BASF MasterRoc MS 685, BASF Construction Chemicals Spain, S.L., Barcelona, Spain) to the cement weight. The mortar of ethyl silicate (ES) was obtained by spraying one coat of ES (SilikatTes $40 \mathrm{WN}$, WackerChemie AG, Munich, Germany) onto the mortar surface with the aid of a nebuliser. 
Mineralogical analysis of the cement was conducted with X-ray diffractions (XRD) using a Bruker D8 Advance diffractometer (Bruker Española S.A., Madrid, Spain). The spectrum was registered with stepping intervals from $4^{\circ}$ to $60^{\circ}$ at $0.05^{\circ}$ in the $\Theta$ - $\Theta$ mode (X-ray tube power: $40 \mathrm{kV}$ and $30 \mathrm{~mA}$ ). The XRD showed that the cement is composed of alite $\left(C_{3} S\right)$, belite $\left(C_{2} S\right)$, tetracalciumaluminoferrite $\left(\mathrm{C}_{4} \mathrm{AF}\right)$, calcite, and gypsum (see Figure 1). Moreover, the chemical composition of the cement was studied with X-ray fluorescence (XRF)with a Philips magic pro spectrometer (Philips Ibérica, Madrid, Spain);the main elements are shown in Table 1.

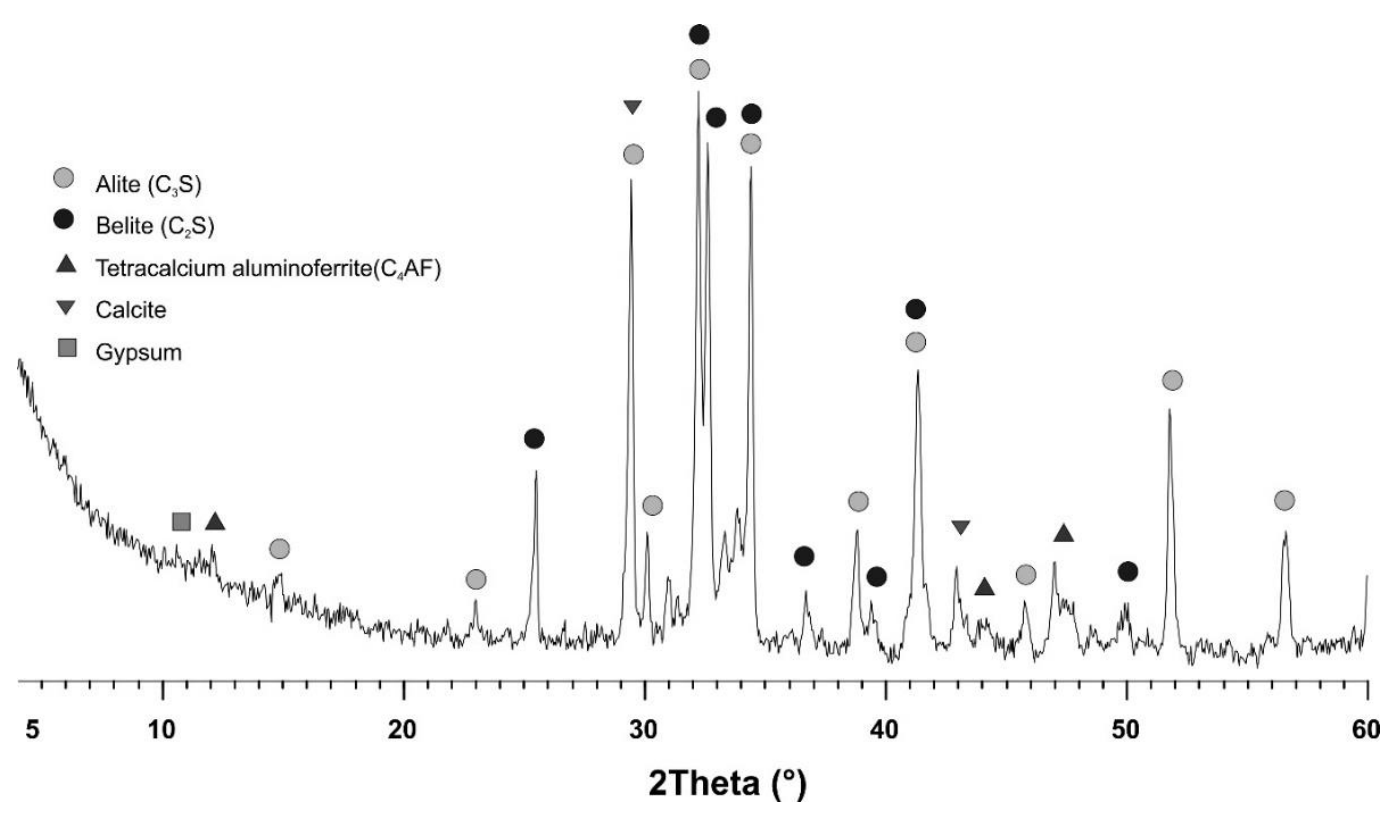

Figure 1. X-ray diffraction (XRD) spectra of cement type CEM I 52.5.

Table 1. X-ray fluorescence of CEM I 52.5R.

\begin{tabular}{cc}
\hline Element & Percentage (\%) \\
\hline $\mathrm{CaO}$ & 55.36 \\
$\mathrm{SiO}_{2}$ & 14.89 \\
$\mathrm{SO}_{3}$ & 4.62 \\
$\mathrm{Al}_{2} \mathrm{O}_{3}$ & 3.36 \\
$\mathrm{MgO}$ & 3.29 \\
$\mathrm{Fe}_{2} \mathrm{O}_{3}$ & 3.06 \\
$\mathrm{~K}_{2} \mathrm{O}$ & 1.06 \\
$\mathrm{TiO}_{2}$ & 0.25 \\
$\mathrm{Na}_{2} \mathrm{O}$ & 0.23 \\
$\mathrm{P}_{2} \mathrm{O}_{5}$ & 0.14 \\
$\mathrm{SrO}$ & 0.12 \\
$\mathrm{Cl}$ & 0.11 \\
$\mathrm{MnO}$ & 0.04 \\
Other elements & $<0.30$ \\
\hline
\end{tabular}

\section{Methods}

\subsection{Manufacturing of Specimens, Curing Process, and Sulphuric Acid Exposure}

Prismatic specimens, according to the UNE-EN 196-1 standard [23], using standardised moulds for cement mortars $(4 \times 4 \times 16 \mathrm{~cm})$, were manufactured to carry out the tests. Six specimens were made for each type of mortar (control, NS, ZS, and ES mortars), obtaining a total of 24 specimens. The specimens were removed from the moulds after $24 \mathrm{~h}$ and stored in a humid chamber $(95 \pm 2 \% \mathrm{RH}$, $20 \pm 2{ }^{\circ} \mathrm{C}$ ) until the curing process (28 days) is completed. The specimens, to which the ES coating had 
to be applied, were extracted from the humid chamber at 14 days. The treatment was applied with the aid of a nebuliser in the stipulated time. The specimens were then returned to the humid chamber to complete the curing period. Twelve specimens were then exposed to a sulphuric acid attack and the other 12 were kept under laboratory conditions $\left(24 \pm 2{ }^{\circ} \mathrm{C}\right)$ and used as reference.

There is no standardised European methodology to evaluate the chemical resistance of cementitious materials. The methodology followed in this study for sulphuric acid exposure has already been used in previous studies $[3,24,25]$. The specimens were immersed in a solution $(3 \% \mathrm{w} / \mathrm{w})$ of sulphuric acid $\left(\mathrm{H}_{2} \mathrm{SO}_{4}\right)$, which was changed weekly. Before the specimens were re-immersed, they were washed with tap water and brushed to remove the layer of adhering material on the mortars' surfaces. In this study, tests of the specimens were conducted after 28 days of acid exposure (i.e., 56 days after their manufacture) and 90 days of exposure (118 days after their manufacture). In each test, three replicates were carried out to obtain average values. Porosimetry was performed for two samples at 90 days of sulphuric acid exposure, due to its repeatability.At the end of the acid exposure, the mortars were washed and dried at $105 \pm 2{ }^{\circ} \mathrm{C}$ for $24 \mathrm{~h}$. Before starting any test, the specimens were left to cool down at room temperature.

\subsection{Mercury Intrusion Porosimetry}

The porosimetry of the mortars (control and treated) was evaluated with a porosimeter model-Poremaster-60 GT of Quantachrome Instruments. This technique is commonly used to assess the efficiency of treatments utilised in cementitous materials exposed to aggressive environments [26,27]. The technique allows obtaining information about the pore structure of a material with an accessible pore diameter, from $4 \mathrm{~nm}$ to $900 \mu \mathrm{m}$. To perform the tests, samples were taken from the surface of the mortars at 90 days of sulphuric acid exposure. They were dried at $50{ }^{\circ} \mathrm{C}$ for $24 \mathrm{~h}$ before the test. Total porosity, pore size distribution, and mercury retained at the end of the experiment were studied. The measuring conditions ranged from atmospheric pressure to 60,000 psi (413.7 MPa).

\subsection{Compressive Strength}

Mechanical strength tests are commonly used to evaluate the effects of chemical exposures on cementitious materials $[26,28,29]$. In this study, the compressive strength of the specimens was tested after 28 days of acid exposure (i.e., 56 days after their manufacture) and 90 days of exposure (118 days after their manufacture) for both control and treated mortars. For each mortar and testing time, six $40 \mathrm{~mm} \times 40 \mathrm{~mm} \times 160 \mathrm{~mm}$ prisms were manufactured. The tests were conducted according to the UNE-EN 196-1 standard [23].

\subsection{Mass Loss}

As with compressive strength, mass loss is also a parameter that is usually measured to assess the impact of aggressive environments on cementitious materials $[25,28]$. In this study, the specimens were weighed three times: (i) after 28 days of curing and before starting the sulphuric acid exposure; (ii) after 28 days of acid exposure (56 days from their manufacture), and (iii) after 90 days of exposure acid (118 days after their manufacture). This test was carried out with the 12 specimens that were immersed in the sulphuric acid solution (three specimens for each type of treatment: control, ethyl silicate, zinc stearate, and nanosilica). The procedure for weighing the specimens was as follows: they were extracted from the acid solution, washed with tap water, and brushed to remove the layer of adhered material on the surface. They were then superficially dried with a towel and placed in an oven for $24 \mathrm{~h}$ at $105 \pm 2{ }^{\circ} \mathrm{C}$. After that, they were allowed to cool for $1 \mathrm{~h}$ and weighed. Finally, they were submerged in the solution to continue with the chemical attack. Thepercentage of mass loss was obtained, taking as reference the weight of the specimens after 28 days of curing (before starting the acid exposure). 


\subsection{Open Porosity}

Open porosity is an important feature in cementitious materials, since it directly influences the durability of these materials, as the larger the open porosity, the greater is the vulnerability to aggressive environments [3]. Open porosity was obtained according to the UNE-EN 1936 standard [30] and calculated by means of the ratio, in percentage, of the volume of open pores and the apparent volume of the specimen, with the following equation:

$$
\rho_{o}=\frac{m_{s}-m_{d}}{m_{s}-m_{h}} \times 100
$$

where:

$\rho_{o}$ is the open porosity $(\%)$

$m_{S}$ is the mass of the saturated sample (g)

$m_{d}$ is the mass of the dry sample $(\mathrm{g})$

$m_{h}$ is the mass of the sample submerged in water $(\mathrm{g})$

\section{Results and Discussion}

\subsection{Mercury Intrusion Porosimetry}

The total porosity values obtained for the studied specimens at 90 days can be observed in Table 2 . In the exposure medium column, "no attack" refers to samples hardened in laboratory conditions and "attack" refers to those exposed to the sulphuric acid attack.

Table 2. Porosity results at 90-day exposure.

\begin{tabular}{ccc}
\hline Mortar Type & Exposure Medium & Total Porosity (\%) \\
\hline \multirow{2}{*}{ Control } & No attack & 10.1 \\
& Attack & 8.6 \\
\hline \multirow{2}{*}{ Ethyl silicate } & No attack & 10.0 \\
& Attack & 11.7 \\
\hline \multirow{2}{*}{ Zinc stearate } & No attack & 13.5 \\
& Attack & 11.1 \\
\hline \multirow{2}{*}{ Nanosilica } & No attack & 9.4 \\
& Attack & 9.9 \\
\hline
\end{tabular}

First, the total porosityof all the mortars had similar magnitude, independently, in the acid attack. In relation to those stored in optimallaboratory conditions (without attack), the lowest total porosity values were noted for the specimens with nanosilica. This result shows a slightly beneficial effect of this addition in terms of porosity, which agrees with another study in which nanosilica has been used [28]. The control and ethyl silicate specimens had practically the same total porosity when not exposed to the acid attack. This result was expected in view of the fact that the ethyl silicate was applied by spraying on the surface of the sample, whereas the rest of the admixtures analysed in this work were incorporated during the setting of the specimens. Therefore, the effects of the ethyl silicate in the total porosity of the global material were less noticeable, especially when it was not exposed to harmful conditions. Finally, for this optimalcondition, the highest total porosity corresponded to the mortars with zinc stearate.

Regarding the total porosity of the mortars exposed to the sulphuric acid attack, the lowest values were noted for the control specimens, followed by the nanosilica ones. On the other hand, the highest values of this parameter were observed for the zinc stearate and ethyl silicate samples.

With respect to the effects of the abovementioned attack on the total porosity of each material, small variations of this parameter were observed. In the case of control and zinc stearate mortars, total 
porosity showed slightly lower values for the samples exposed to the sulphuric acid attack, compared to the optimal condition ones. On the contrary, for the ethyl silicate specimens, this parameter was higher when subjected to the harmful condition. For nanosilica mortars, the attack hardly had an effect on total porosity.

The pore size distributions in fixed diameter intervals $-<10 \mathrm{~nm}, 10-100 \mathrm{~nm}, 100 \mathrm{~nm}-1 \mu \mathrm{m}$, 1-10 $\mu \mathrm{m}, 10 \mu \mathrm{m}-0.1 \mathrm{~mm}$, and $>0.1 \mathrm{~mm}$-were also studied. These distributions for the studied mortars can be observed in Figure 2. In addition, the volume of each pore interval for the studied samples is compiled in Table 3. Regarding the control mortars, the volume of pores with diameters higher than $100 \mathrm{~nm}$ hardly changed between the samples exposed to the sulphuric acid attack and those hardened in the optimal condition. On the other hand, a noticeable decrease in the volume of smaller pores (diameters lower than $100 \mathrm{~nm}$ ) in the control samples subject to the acid attack was observed, compared to those without the attack. Therefore, the previously described reduction of total porosity for control mortars exposed to the attack could be related to the abovementioned decrease of overall volume of pores of diameter ranges lower than $100 \mathrm{~nm}$. In view of this, it can be pointed out that the sulphuric acid attack produced a less-refined microstructure in control mortars, with a predominance of pores of higher sizes. This could be indicative of the damage causedby this attack, which entails a progressive dissolution of Portlandite and decomposition of C-S-H phases [31], as well as the formation of expansive products $[27,32,33]$, which can cause microcracking of the pore network of the material, reducing its refinement (increasing the proportion of higher pores) and making it more accessible to aggressive substances.

In relation to the ethyl silicate specimens (as occurred with the control mortars), the volume of pores with diameters greater than $100 \mathrm{~nm}$ slightly altered between the samples exposed to the acid attack and those hardened in the optimal condition. Nevertheless, for specimens in which this solution was applied, pores with diameters lower than $100 \mathrm{~nm}$ showed an increase in volume in contact with the aggressive medium. The rise of total porosity obtained for the ethyl silicate mortars exposed to the attack could thus be due to that increase in volume of pores with sizes $<100 \mathrm{~nm}$. It can, therefore, be noted that the pore structure of samples with ethyl silicate became more refined after 90 days of exposure to the sulphuric acid attack, compared to those without, despite being more porous. The global increase in intrusion volume, and consequently in total porosity, for the ethyl silicate exposed to the sulphuric acid condition shows the harmful effects of the attack [2,4]. In addition, the rise in volume of finer pores are also indicative of this attack, and represents a part of the pore network in which the attacksdevelops at the studied exposure age. As has been explained, ethyl silicate reacts with the material to which it is applied, producing pozzolanic solid phases [18]. In the initial steps of the sulphuric acid attack, these pozzolanic products react with the aggressive ions, leading to the formation of ettringite and gypsum [4,5] which progressively fill the pores, reducing their sizes. This takes place in part of the microstructure of ethyl silicate samples, as suggested by the pore size distributions obtained (see Figure 2). In further stages of the attack, once all the pores are completely filled, and with a continuous formation of expansive products, it is expected that the degradation of the microstructure of the material is complete [34].

Their behaviourof the zinc stearate specimens with regards to pore size distributions is relatively similar to that observed for the control mortar samples, although with higher values of global intrusion volume and total porosity. The volume of pores with diameters higher than $100 \mathrm{~nm}$ wasfound to be very similar for the zinc stearate specimens exposed to the acid attack than for those that were not subject to the attack. On the contrary, for the samples exposed to the acid attack, a reduction in volume of pores lower than $100 \mathrm{~nm}$ was observed. Therefore, the acid attack produced a higher proportion of greater pores in the zinc stearate mortars, limitingthe refinement of their microstructure [2,4].

Regarding mortars with nanosilica, minute changes were observed in pore size distribution, when the results obtained for specimens exposed to the optimal condition and the acid attack are compared. The main variations were a slight decrease in the volume of pores $<10 \mathrm{~nm}$ and a small rise in the volume of pores with diameters in the range of $10-100 \mathrm{~nm}$. In view of this result, it seems that the 
microstructural effects of the sulphuric acid attack were still emerging at the studied age for nanosilica mortars, particularly with regards to the accuracy and limitations of the mercury intrusion porosimetry technique used to study this type of attack [34-36].

Finally, if the different studied mortars exposed to the acid attack are compared, it is important to emphasise that those with ethyl silicate, zinc stearate, and nanosilica showed a more refined microstructure, with higher proportion of smaller pores (diameters lower than $100 \mathrm{~nm}$ ) compared to the control mortars, despite their greater global intrusion volume and total porosity.

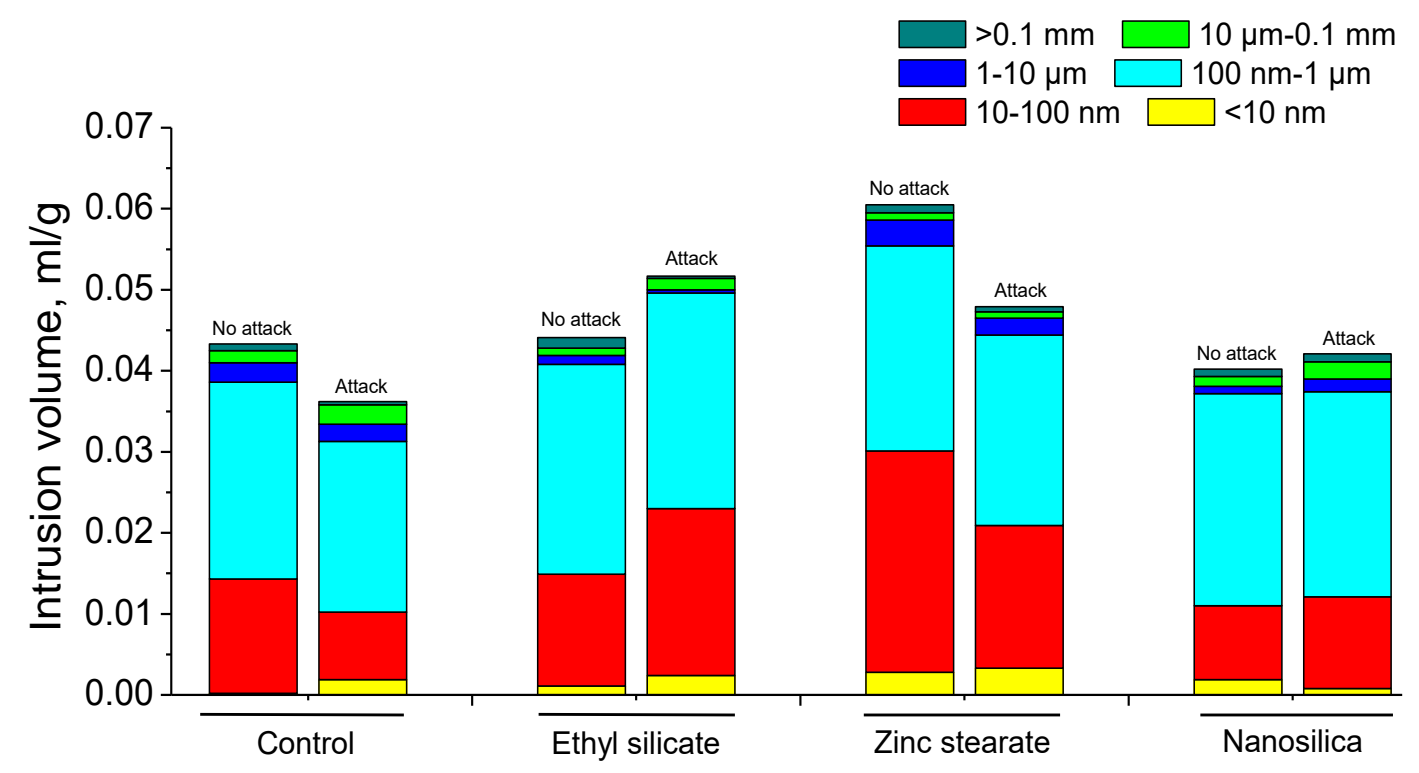

Figure 2. Pore size distribution of the studied mortars at 90-day exposure. The samples referred to as "no attack" are those that were hardened in a non-aggressive environment and the specimens labelled as "attack" are those that were exposed to sulphuric acid.

Table 3. Volume $(\mathrm{mL} / \mathrm{g})$ of each pore interval for the studied samples.

\begin{tabular}{ccccccccc}
\hline & \multicolumn{2}{c}{ Control } & \multicolumn{2}{c}{ Ethyl Silicate } & \multicolumn{2}{c}{ Zinc Stearate } & \multicolumn{2}{c}{ Nanosilica } \\
\hline & No Attack & Attack & No Attack & Attack & No Attack & Attack & No Attack & Attack \\
\hline$<10 \mathrm{~nm}$ & 0.0002 & 0.0019 & 0.0011 & 0.0024 & 0.0028 & 0.0033 & 0.0019 & 0.0008 \\
$10-100 \mathrm{~nm}$ & 0.0141 & 0.0083 & 0.0138 & 0.0206 & 0.0273 & 0.0176 & 0.0091 & 0.0113 \\
$100 \mathrm{~nm}-1 \mu \mathrm{m}$ & 0.0243 & 0.0211 & 0.0259 & 0.0266 & 0.0253 & 0.0235 & 0.0262 & 0.0253 \\
$10-100 \mu \mathrm{m}$ & 0.0024 & 0.0021 & 0.0011 & 0.0004 & 0.0032 & 0.0021 & 0.0009 & 0.0016 \\
$10 \mu \mathrm{m}-0.1 \mathrm{~mm}$ & 0.0015 & 0.0024 & 0.0009 & 0.0014 & 0.0009 & 0.0008 & 0.0012 & 0.0021 \\
$>0.1 \mathrm{~mm}$ & 0.0008 & 0.0004 & 0.0013 & 0.0003 & 0.0010 & 0.0006 & 0.0009 & 0.0010 \\
\hline
\end{tabular}

The results of mercury $(\mathrm{Hg})$ retained after the end of the porosimetry test at 90 days of exposure to the optimal ("no attack") and sulphuric acid aggressive ("attack") conditions are compiled in Table 4. This parameter provides qualitative information on the evolution of the microstructure $[37,38]$-its tortuosity and the progressive closure of pores.

For the mortars and conditions studied in this research, the values of $\mathrm{Hg}$ retained had a similar order of magnitude. For the control mortars, this parameter was higher for those subjected to the sulphuric acid attack, compared to those exposed to the optimal condition. This result could be related to the damage caused in the pore network by the acid attack. As has been explained before, degradation of the microstructure due to this attack $[4,29,39]$ results in the formation of microcracks. This microcracking phenomenon modifies the internal surface of the pores, increasing this surface [40] and consequently the tortuosity of the pore network. This result is in line with the loss of microstructure refinement observed in the control mortars with the attack (discussed earlier). 
Table 4. Mercury (Hg) retained at the end of the experiment after the 90-day exposure.

\begin{tabular}{ccc}
\hline Mortar Type & Exposure Medium & Hg Retained (\%) \\
\hline \multirow{2}{*}{ Control } & No attack & 47.8 \\
& Attack & 53.9 \\
\hline \multirow{2}{*}{ Ethyl silicate } & No attack & 62.1 \\
& Attack & 47.8 \\
\hline \multirow{2}{*}{ Zinc stearate } & No attack & 55.7 \\
& Attack & 57.4 \\
\hline \multirow{2}{*}{ Nanosilica } & No attack & 57.5 \\
& Attack & 53.9 \\
\hline
\end{tabular}

For the ethyl silicate mortars, a reduction in the retained $\mathrm{Hg}$ was noted when subjected to the acid attack, as compared those exposed to the optimal condition. An increase in pore refinement of this type of mortar, subjected to attack by the acid, was observed, with a high percentage of finer pores. This is in agreement with the decrease of $\mathrm{Hg}$ reduction under the same conditions and can be explained in relation to the silting of the pores by the formation of ettringite and gypsum, whichare produced by a reaction of the pozzolanic products (caused by the sprayed ethyl silicate) with the aggressive ions $[4,5]$. This process closes the microstructure, reducing its tortuosity, at least until they are filled (when the microcracking phenomenon is predominant).

In relation to zinc stearate mortars, the $\mathrm{Hg}$ retained was found to be slightly higher for samples exposed to the acid attack than for those in contact with the non-aggressive environment. This result is in line with the lower microstructure refinement shown by zinc stearate mortars subject to the acid attack. As was with control mortars, this could be due to the formation of microcracks [29,41,42], which increase the pore surface [40], resulting in a higher tortuosity of the microstructure.

Regarding the nanosilica mortars, those exposed to the acid attack showed slightly lower retained $\mathrm{Hg}$, compared to those stored in conditions that do not have aggressive substances. This result is in line with the total porosity and pore size distribution obtained for these additions. This lower value is indicative of a possible process of pore silting, which could reduce tortuositydue to closure of the microstructure. However, this also suggests that, simultaneous to the abovementioned silting process in pores that still have free space, there could be pores that are completely filled by expansive products. In such a situation, the continuous effect of the attack will form microcracks, breaking the pore walls and increasing the tortuosity of the pore network, subsequently increasing the amount of retained Hg. In global terms, this shows that the reduction of this parameter is relatively small in nanosilica specimens subject to the acid attack, compared to those exposed to the non-aggressive environment.

\subsection{Compressive Strength}

The study revealed that in a non-aggressive environment, compressive strength increased from 28 days to 90 days for all types of mortars (Figure 3). This strength increaseis normal in cement-based materials after having been properly cured, provided that they have been maintained in a non-aggressive environment $[25,43]$. 


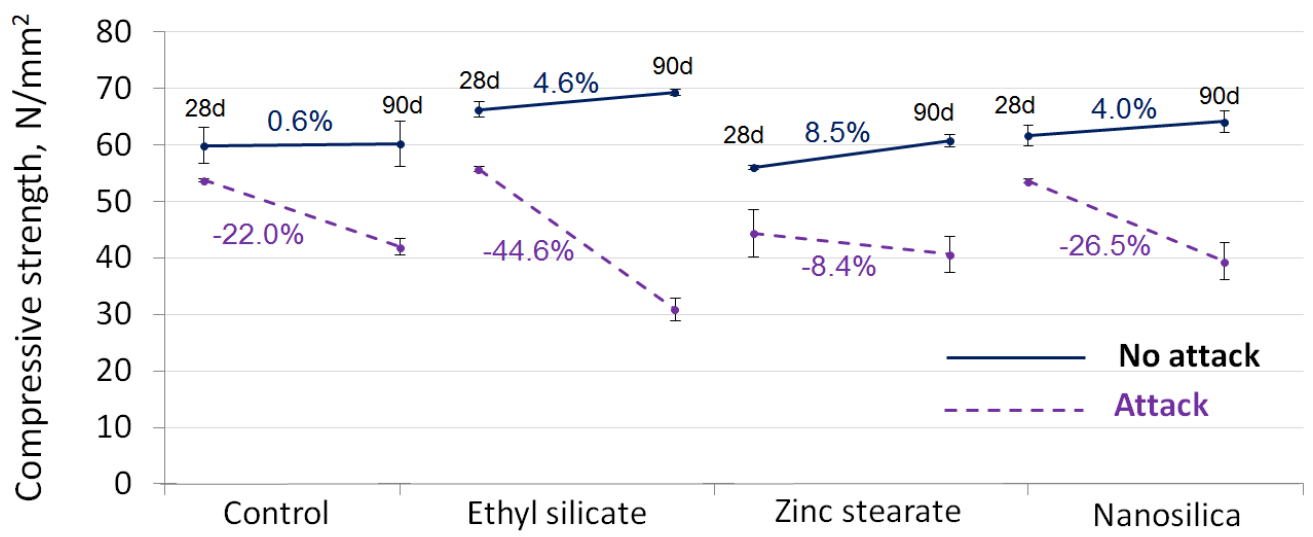

Figure 3. Compressive strength variation of the mortars analysed as a function of time and environmental conditions (sulphuric acid attack and non-aggressive environment). Error bars represent standard deviation.

However, in this study, the control mortar showed an insignificantincrease in compressive strength from 28 to 90 days $(0.6 \%$ ), while the other mortars showed an appreciable increase (about $4 \%$ observed in the mortars treated with ethyl silicate and nanosilica mortars). Mortars with zinc stearate had the highest increase in compressive strength at 90 days (8.5\%). However, they exhibited a higher difference between compressive strength obtained at 28 days and that obtained at 90 days; they also displayed the strongest influence on hydration andslowed down hydration reactions [44], subsequently influencing mechanical properties.

On the contrary, when the mortars were exposed to a sulphuric acid attack, compressive strength decreased from 28 to 90 days. The largest loss of strength occurred in the ES mortar (44.6\%) and the lowest in the ZS mortar (8.4\%). A reduction in resistance to the sulphuric acid attack was also observed in previous studies [3,28]; this is due to the appearance of expansive compounds that cause microcracking in the mortars. Microcracks are generated on the surface of the mortars, growing towards the interior, thus causing a decrease in mechanical properties $[4,33]$.

\subsection{Mass Loss Caused by Sulphuric Acid Exposure}

The results of mass loss due to the sulphuric acid attack are shown in Figure 4. All the cases showed substantial mass loss. The largest variation occurred for the ethyl silicate mortar with an increase of 30.5 percentage points (pp) (increased from $8.6 \%$ at 28 days to $39.2 \%$ at 90 days), and the zinc stearate mortar was the least affected with an increase in mass loss of 16.8 points. These results are consistent with those obtained in other studies, where cementitious materials were seen to decrease mass with increase in exposure time [3,10,28].

Therefore, as can be seen in Figure 4, the mass loss of control mortars, ethyl silicate, and nanosilica mortars exposed to the same conditions of acid attack was considerably higher than that of the zinc stearate mortar. Calcium compounds in these systems react with the acid solutions, resulting in the decomposition of hydration products and increasing the total porosity, subsequently accelerating the acid attack [45,46]. However, the water-repellent admixture (zinc stearate) was able to enhance the resistance to acid environments because they reduce the affinity of capillary pore surfaces to moisture and slow down mass loss [24]. 


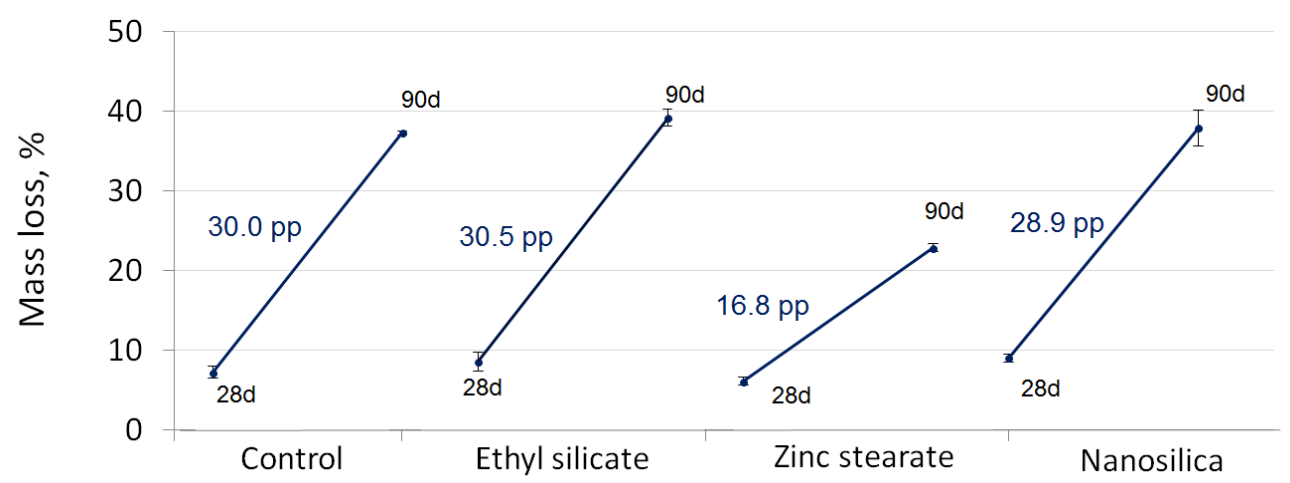

Figure 4. Mass loss variation of the mortars due to a sulphuric acid attack in the period from 28 days to 90 days of exposure. Error bars represent standard deviation.

\subsection{Open Porosity}

Figure 5 shows the effect of the sulphuric acid attack on the open porosity of mortars in the time period between 28 days and 90 days of exposure. It was observed that all the mortars increased porosity at 90 days with respect to porosity at 28 days due to the acid attack. The ethyl silicate mortar was the most affected with an increase in porosity of 9.4 percentage points. The zinc stearate mortar was the least affected with an increment of 7.7 points. These results are coherent with previous studies where it was observed that mortars exposed to acid attacks suffered mass (Figure 6a) and strength losses (Figure 6b) due to the increase in porosity and permeability [47].

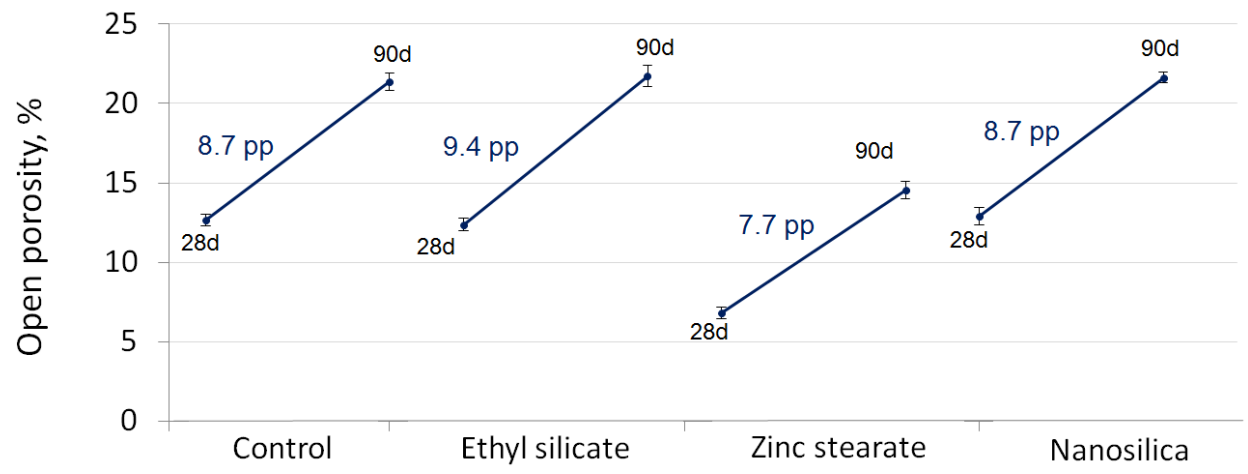

Figure 5. Increase inopen porosity due to a sulphuric acid attack in the period from 28 days to 90 days of exposure.Error bars represent standard deviation.
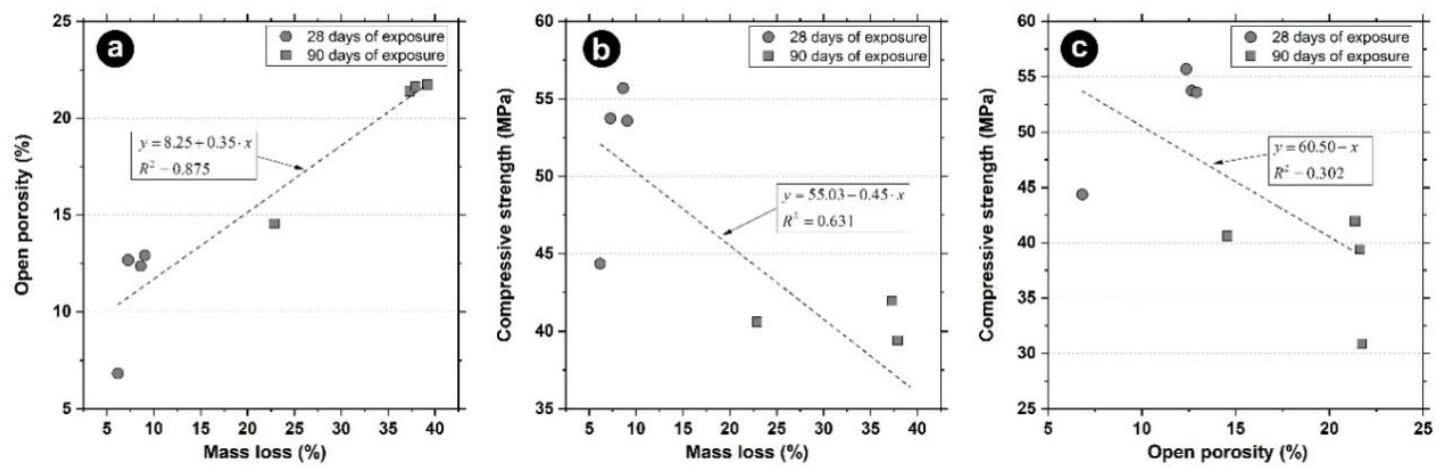

Figure 6. Correlation between (a) mass loss and open porosity, (b) mass loss and compressive strength, and (c) open porosity and compressive strength. 
Figure 6 shows the correlation between mass loss, open porosity, and compressive strength. The good correlation between mass loss and open porosity (Figure 6a) indicates that the higher the open porosity of the mortars, the higher is the mass loss. As can be observed in Figure $6 \mathrm{~b}, \mathrm{c}$, compressive strength is directly related to the deterioration of the mortar, which also depends on the porosity of the cement paste.

\section{Conclusions}

This paper addresses the degradation of different types of cement mortars (with zinc stearate, nanosilica and ethyl silicate coating) exposed to sulphuric acid attack using mercury intrusion porosimetry. The main conclusions are as follows:

- There was a small variation in total porosity for all the mortars; they also were of similar magnitude.

- After the sulphuric acid attack, the control mortars and mortars with zinc stearate showed a less-refined microstructure with a predominance of pores of higher sizes. On the contrary, pore structure was more refined in mortars treated with ethyl silicate coating exposed to the attack. Mortars with nanosilica exhibited limited changes in pore size distribution after the acid exposure, compared to the optimal condition.

- The mercury retained after the end of the porosimetry test was of a similar order of magnitude in all the mortars studied. The control mortar and mortars with ethyl silicate exhibited an increase in retained $\mathrm{Hg}$, probably due to the formation of microcracks, resulting in a higher tortuosity of the microstructure. However, mortars with ethyl silicate coating and nanosilica showed a reduction in retained $\mathrm{Hg}$, probably due to silting of the pores.

- The reduction in compressive strength observed in all the mortars was due to the appearance of expansive compounds that cause microcracking, weakening the structure of the mortars.

- The mortar less affected in terms of open porosity and mass loss after the acid exposure was the one with zinc stearate.

Author Contributions: All the authors contributed to the conceptualization, data curation, formal analysis, funding acquisition, investigation, project administration, supervision, and validation; methodology and writing-original draft, V.E.G.-V.; writing-review and editing, A.J.T.-A., A.M.S., and J.M.O.

Funding: This research was funded by the University of Alicante ((GRE13-03) and (VIGROB-256)).

Acknowledgments: The authors express their thanks to C.T.S. Spain for providing the ethyl silicate used in this study. The authors also acknowledge the University of Alicante Technical Research Services (SSTTI) for the analysis performed using their equipment, which was financed by the EU, MINECO, and Generalitat Valenciana (State Programme for Knowledge Generation and Scientific and Technological Strengthening of the R+D+i System and P.O. FEDER 2007-2013 funds).

Conflicts of Interest: The authors declare no conflict of interest.

\section{References}

1. Quinn, M.-L. Early smelter sites: A neglected chapter in the history and geography of acid rain in the United States. Atmos. Environ. 1989, 23, 1281-1292. [CrossRef]

2. Lanzón, M.; García-Ruiz, P.A. Deterioration and damage evaluation of rendering mortars exposed to sulphuric acid. Mater. Struct. 2010, 43, 417-427. [CrossRef]

3. García-Vera, V.; Tenza-Abril, A.; Saval, J.; Lanzón, M. Influence of crystalline admixtures on the short-term behaviour of mortars exposed to sulphuric acid. Materials 2018, 12, 82. [CrossRef] [PubMed]

4. Skalny, J.; Marchand, J.; Odler, I. Sulfate Attack on Concrete; Spon Press: London, UK; New York, NY, USA, 2002; ISBN 0-419-24550-2.

5. Hadigheh, S.A.; Gravina, R.J.; Smith, S.T. Effect of acid attack on FRP-to-concrete bonded interfaces. Constr. Build. Mater. 2017, 152, 285-303. [CrossRef] 
6. García-Vera, V.E.; Lanzón, M. Physical-chemical study, characterisation and use of image analysis to assess the durability of earthen plasters exposed to rain water and acid rain. Constr. Build. Mater. 2018, 187, 708-717. [CrossRef]

7. Jalal, M.; Pouladkhan, A.; Harandi, O.F.; Jafari, D. Comparative study on effects of Class F fly ash, nano silica and silica fume on properties of high performance self compacting concrete. Constr. Build. Mater. 2015, 94, 90-104. [CrossRef]

8. Norhasri, M.S.M.; Hamidah, M.S.; Fadzil, A.M. Applications of using nano material in concrete: A review. Constr. Build. Mater. 2017, 133, 91-97. [CrossRef]

9. Qing, Y.; Zenan, Z.; Deyu, K.; Rongshen, C. Influence of nano-SiO 2 addition on properties of hardened cement paste as compared with silica fume. Constr. Build. Mater. 2007, 21, 539-545. [CrossRef]

10. Mahdikhani, M.; Bamshad, O.; Fallah Shirvani, M. Mechanical properties and durability of concrete specimens containing nano silica in sulfuric acid rain condition. Constr. Build. Mater. 2018, 167, 929-935. [CrossRef]

11. Khanzadi, M.; Tadayon, M.; Sepehri, H.; Sepehri, M.; Student, M.S. Influence of nano-silica particles on mechanical properties and permeability of concrete. In Proceedings of the Second International Conference on Sustainable Construcion Materials and Technologies, Ancona, Italy, 28-30 June 2010; Zachar, J., Claisse, P., Naik, T.R., Ganjian, E., Eds.; Universita Ploitecnica delle Marche: Ancona, Italy, 2010.

12. Fallah, S.; Nematzadeh, M. Mechanical properties and durability of high-strength concrete containing macro-polymeric and polypropylene fibers with nano-silica and silica fume. Constr. Build. Mater. 2017, 132, 170-187. [CrossRef]

13. Lanzón, M.; García-Ruiz, P.A. Effectiveness and durability evaluation of rendering mortars made with metallic soaps and powdered silicone. Constr. Build. Mater. 2008, 22, 2308-2315. [CrossRef]

14. Lanzón, M.; Martínez, E.; Mestre, M.; Madrid, J.A. Use of zinc stearate to produce highly-hydrophobic adobe materials with extended durability to water and acid-rain. Constr. Build. Mater. 2017, 139, 114-122. [CrossRef]

15. Hashem, F.S. Sulfate attack on hardened Portland cement pastes with different porosities in presence of water-repelling admixtures. Adv. Cem. Res. 2009, 21, 75-82. [CrossRef]

16. Cogan, H.; Setterstrom, C. Ethyl Silicates. Ind. Eng. Chem. 1947, 39, 1364-1368. [CrossRef]

17. Pan, X.; Shi, Z.; Shi, C.; Ling, T.-C.; Li, N. A review on concrete surface treatment Part I: Types and mechanisms. Constr. Build. Mater. 2017, 132, 578-590. [CrossRef]

18. Pigino, B.; Leemann, A.; Franzoni, E.; Lura, P. Ethyl silicate for surface treatment of concrete-Part II: Characteristics and performance. Cem. Concr. Compos. 2012, 34, 313-321. [CrossRef]

19. Sandrolini, F.; Franzoni, E.; Pigino, B. Ethyl silicate for surface treatment of concrete-Part I: Pozzolanic effect of ethyl silicate. Cem. Concr. Compos. 2012, 34, 306-312. [CrossRef]

20. García-Vera, V.E.; Tenza-Abril, A.J.; Lanzón, M. The effectiveness of ethyl silicate as consolidating and protective coating to extend the durability of earthen plasters. Constr. Build. Mater. 2020, 236, 117445. [CrossRef]

21. AENOR UNE-EN 197-1:2011. Cement-Part 1: Composition, Specifications and Conformity Criteria for Common Cements; AENOR: Madrid, Spain, 2011.

22. AENOR UNE-EN 933-1:2012. Tests for Geometrical Properties of Aggregates-Part 1: Determination of Particle Size Distribution-Sieveing Method; AENOR: Madrid, Spain, 2012.

23. AENOR UNE-EN 196-1:2005. Methods of Testing Cement-Part 1: Determination of Strength; AENOR: Madrid, Spain, 2005.

24. Soroushian, P.; Chowdhury, H.; Ghebrab, T. Evaluation of water-repelling additives for use in concrete-based sanitary sewer infrastructure. J. Infrastruct. Syst. 2009, 15, 106-110. [CrossRef]

25. García-Vera, V.E.; Tenza-Abril, A.J.; Lanzón, M.; Saval, J.M. Exposing sustainable mortars with nanosilica, zinc stearate, and ethyl silicate coating to sulfuric acid attack. Sustainability 2018, 10, 3769. [CrossRef]

26. Ortega, J.M.; Esteban, M.D.; Williams, M.; Sánchez, I.; Climent, M.A. Short-term performance of sustainable silica fume mortars exposed to sulfate attack. Sustainability 2018, 10, 2517. [CrossRef]

27. Ortega, J.; Esteban, M.; Rodríguez, R.; Pastor, J.; Ibanco, F.; Sánchez, I.; Climent, M. Influence of silica fume addition in the long-term performance of sustainable cement grouts for micropiles exposed to a sulphate aggressive medium. Materials 2017, 10, 890. [CrossRef] [PubMed]

28. Deb, P.S.; Sarker, P.K.; Barbhuiya, S. Sorptivity and acid resistance of ambient-cured geopolymer mortars containing nano-silica. Cem. Concr. Compos. 2016, 72, 235-245. [CrossRef] 
29. Bonakdar, A.; Mobasher, B. Multi-parameter study of external sulfate attack in blended cement materials. Constr. Build. Mater. 2010, 24, 61-70. [CrossRef]

30. AENOR UNE-EN 1936:2007. Natural Stone Test Methods-Determination of Real Density and Apparent Density, and of Total and Open Porosity; AENOR: Madrid, Spain, 2007.

31. Tixier, R.; Mobasher, B. Modeling of damage in cement-based materials subjected to external sulfate attack. I: Formulation. J. Mater. Civ. Eng. 2003, 15, 305-313. [CrossRef]

32. Huang, Q.; Wang, C.; Yang, C.; Zhou, L.; Yin, J. Accelerated sulfate attack on mortars using electrical pulse. Constr. Build. Mater. 2015, 95, 875-881. [CrossRef]

33. Ma, H.; Li, Z. Microstructures and mechanical properties of polymer modified mortars under distinct mechanisms. Constr. Build. Mater. 2013, 47, 579-587. [CrossRef]

34. Ortega, J.; Esteban, M.; Rodríguez, R.; Pastor, J.; Ibanco, F.; Sánchez, I.; Climent, M. Long-term behaviour of fly ash and slag cement grouts for micropiles exposed to a sulphate aggressive medium. Materials 2017, 10, 598. [CrossRef]

35. Diamond, S. Mercury porosimetry. An inappropriate method for the measurement of pore size distributions in cement-based materials. Cem. Concr. Res. 2000, 30, 1517-1525. [CrossRef]

36. Diamond, S. Aspects of concrete porosity revisited. Cem. Concr. Res. 1999, 29, 1181-1188. [CrossRef]

37. Cabeza, M.; Merino, P.; Miranda, A.; Nóvoa, X.R.; Sanchez, I. Impedance spectroscopy study of hardened Portland cement paste. Cem. Concr. Res. 2002, 32, 881-891. [CrossRef]

38. Williams, M.; Ortega, M.; Sánchez, I.; Cabeza, M.; Climent, M.A. Non-destructive study of the microstructural effects of sodium and magnesium sulphate attack on mortars containing silica fume using impedance spectroscopy. Appl. Sci. 2017, 7, 648. [CrossRef]

39. Santhanam, M.; Cohen, M.D.; Olek, J. Mechanism of sulfate attack: A fresh look. Part 1: Summary of experimental results. Cem. Concr. Res. 2002, 32, 915-921. [CrossRef]

40. Ortega, J.M.; Sánchez, I.; Climent, M.A. Impedance spectroscopy study of the effect of environmental conditions in the microstructure development of OPC and slag cement mortars. Arch. Civ. Mech. Eng. 2015, 15, 569-583. [CrossRef]

41. Neville, A. The confused world of sulfate attack on concrete. Cem. Concr. Res. 2004, 34, 1275-1296. [CrossRef]

42. Santhanam, M.; Cohen, M.D.; Olek, J. Mechanism of sulfate attack: A fresh look-Part 2. Proposed mechanisms. Cem. Concr. Res. 2003, 33, 341-346. [CrossRef]

43. Jiménez Montoya, P.; García Meseguer, A.; Morán Cabré, F. Hormigón Armado, 14th ed.; Gustavo Gili: Barcelona, Spain, 2000; ISBN 9788425218255.

44. Falchi, L.; Zendri, E.; Muller, U.; Fontana, P. The influence of water-repellent admixtures on the behaviour and the effectiveness of Portland limestone cement mortars. Cem. Concr. Compos. 2015, 59, 107-118. [CrossRef]

45. Duan, P.; Yan, C.; Zhou, W.; Luo, W.; Shen, C. An investigation of the microstructure and durability of a fluidized bed fly ash-metakaolin geopolymer after heat and acid exposure. Mater. Des. 2015, 74, 125-137. [CrossRef]

46. Vafaei, M.; Allahverdi, A.; Dong, P.; Bassim, N. Acid attack on geopolymer cement mortar based on waste-glass powder and calcium aluminate cement at mild concentration. Constr. Build. Mater. 2018, 193, 363-372. [CrossRef]

47. Kwasny, J.; Aiken, T.A.; Soutsos, M.N.; McIntosh, J.A.; Cleland, D.J. Sulfate and acid resistance of lithomarge-based geopolymer mortars. Constr. Build. Mater. 2018, 166, 537-553. [CrossRef]

(C) 2019 by the authors. Licensee MDPI, Basel, Switzerland. This article is an open access article distributed under the terms and conditions of the Creative Commons Attribution (CC BY) license (http://creativecommons.org/licenses/by/4.0/). 